\title{
INFLUENCE OF EXTRACTION CONDITIONS ON ANTIOXIDANT PROPERTIES OF PASSION FRUIT (PASSIFLORA EDULIS) PEEL
}

\author{
Yuh Shan Wong ${ }^{1}$, Chiaw Mei Sia ${ }^{1}$, Hock Eng Khoo ${ }^{1,2}$, Yee Kwang Ang ${ }^{3}$, \\ Sui Kiat Chang ${ }^{2}$, Hip Seng Yim ${ }^{1 \bowtie}$ \\ ${ }^{1}$ Department of Food Science and Nutrition, Faculty of Applied Sciences, UCSI University \\ No. 1 Jalan Menara Gading, UCSI Heights, 56000 Kuala Lumpur, Malaysia \\ 2Department of Nutrition and Dietetics, Faculty of Medicine and Health Sciences, Universiti Putra Malaysia \\ 43400 UPM Serdang, Selangor, Malaysia \\ ${ }^{3}$ Perdana University Graduate School of Medicine, Block B and D1, MAEPS Building, MARDI Complex \\ 43400 Serdang, Selangor, Malaysia
}

\begin{abstract}
Background. As a by-product of tropical fruit juice industry, passion fruit peel is a valuable functional food. It is rich in antioxidants. To determine its potential antioxidant properties of passion fruit peel, this study aimed to evaluate the effect of extraction conditions on total phenolic content and antioxidant activity.

Methods. The extraction conditions were selected from different percentages of ethanol $(0-100 \%, v / v)$, extraction times $(60-300 \mathrm{~min})$, and extraction temperatures $\left(25-60^{\circ} \mathrm{C}\right)$ that based on the optimal percentage of DPPH radical scavenging activity. The selected extraction condition was applied for further determination of total phenolic content (TPC) of the passion fruit peel extract using Folin-Ciocalteu reagent assay, while the antioxidant activities were evaluated using DPPH and ABTS radicals scavenging assays, ferric reducing antioxidant power (FRAP), and $\beta$-carotene bleaching (BCB) assay. The best extraction conditions were $40 \%$ ethanol, 60 min extraction time, and extraction temperature of $30^{\circ} \mathrm{C}$.

Results. The chosen extraction conditions have contributed to the high TPC and antioxidant activity of passion fruit peel. The levels of antioxidant activity obtained from the passion fruit peel were also lower compared to BHA and $\alpha$-tocopherol. Positive correlations were observed between TPC and antioxidant activities as assessed by DPPH, ABTS, FRAP, and BCB assays.

Conclusion. As a waste of passion fruit consumption or by-product of fruit juice industry, its peel could be considered as a potential source of natural antioxidant for possible functional food and industrial applications.
\end{abstract}

Key words: antioxidant capacity, extraction temperature, extraction time, passion fruit, total phenolic content

\section{INTRODUCTION}

Diet containing enough servings of fruits helps to maintain human health by its numerous antioxidants. In nature, fruit is rich in antioxidants as it is subjected to severe oxidative stress [Mittler et al. 2011]. Antioxidants in fruit have been reported to reduce oxidative damage in our body [Halliwell 2012]. The antioxidants are known to play an important role in ameliorating oxidation process by quenching free radicals, chelating metals and scavenging oxygen in foods and biological systems [Anwar and Przybylski 2012]. Tropical fruits have high antioxidants and the major antioxidants in these fruits are phenolic compounds. Passion fruit 
(Passiflora edulis), which belongs to the family Passifloraceae, is one of the tropical fruits in Southeast Asia. Passion fruit is small, egg-like in shape, and about $5-8 \mathrm{~cm}$ in diameter that grow on long, trailing vines [Janick and Paull 2008]. The fruit is either yellow or dark purple colour when matured, with a soft to firm, juicy interior filled with numerous dark brown (for yellow form) or black (for purple form), pitted seeds. The peel of passion fruit becomes hardens and wrinkles during maturity [Hooper 1994]. The purple coloured passion fruit has more pleasant flavour than the yellow one. Yellow passion fruit is usually used for food processing [Janick and Paull 2008]. Passion fruit is a good source of vitamins, minerals, dietary fiber, and phytochemicals such as flavonoids [Janick and Paull 2008, Yapo and Koffi 2008].

The presence of numerous antioxidant phytochemicals in passion fruit contributes to its therapeutic significance. One tonne of passion fruit is known to produce about $300 \mathrm{~kg}$ of juice, $110 \mathrm{~kg}$ of seeds, 320 $\mathrm{kg}$ of inner peel and $225 \mathrm{~kg}$ of outer peel. This shows that the inedible parts of passion fruit are more than the edible portion [Sai-Ut et al. 2010]. Studies reported that fruit peels have higher antioxidant activity as compared to the pulp [Shui and Leong 2006, Gonzalez-Montelongo et al. 2010, Babbar et al. 2011]. Oral administration of passion fruit peel extracts was found to reduce wheeze and cough in asthma adults [Watson et al. 2008], reduce pain and stiffness in adult patients with knee osteoarthritis [Farid et al. 2010], and alleviating hypertension [Zibadi at al. 2007]. Fruit peel has also been described as waste of fruit consumption or by-product of food processing. Fully utilization of fruit peels as cattle feed will help to reduce waste materials from agro-food industries, as well as effective utilization of inexpensive natural sources for nutritional and functional purposes.

Extraction is an important process for isolation of phenolic antioxidants from fruit [Lapornik et al. 2005]. Extraction parameters such as type of solvent, solvent concentration, extraction temperature, extraction time, and solvent-to-solid ratio are the major consideration for enhancement of extraction efficiency to obtain optimal amount of bioactive compounds in the extract [Pinelo et al. 2005, Naczk and Shahidi 2006, Spigno et al. 2007]. Different drying methods used have also been reported to affect the antioxidant activity of fruits and vegetables [Choi et al. 2006, Chantaro et al. 2008, Kuljarachanan et al. 2009, Suvarnakuta et al. 2011]. To the best of our knowledge, studies on the effect of different extraction conditions on antioxidants in fruit peel are still scarce. Each extraction condition should be applied to single type of fruit sample. As different type of fruit sample has its own range of phytochemical content, therefore, this study aimed to investigate the influence of different extraction conditions on DPPH (2,2-diphenyl-1-picrylhydrazyl) radical scavenging activity for passion fruit peel. The study also aimed to determine total phenolic content and antioxidant activities of the passion fruit peel based on the best extraction condition.

\section{MATERIAL AND METHODS}

Sample preparation. Passion fruit was purchased from a local farmer in Bukit Tinggi, Pahang, Malaysia. Only fresh passion fruit without damages was selected. The fruit was washed under running tap water and its peel was separated from pulp. The passion fruit peels were cut into pieces of $1 \mathrm{~cm}^{3}$ uniformly and oven-dried using an universal oven UFB 500 (Memmert GmbH \& Co. KG, Schwabach, Germany) at oven temperature of $45^{\circ} \mathrm{C}$ until a constant weight obtained. Before extraction, the oven-dried samples were ground into powder form using a laboratory grinder and vacuumpacked using a DZQ 400/500 single vacuum chamber packager (Rotech Pharmaceutical Engineering Co., Ltd., Shanghai, China). The sample was stored at $-20^{\circ} \mathrm{C}$ before further analyses.

Sample extraction. The passion fruit peel powder $(5 \mathrm{~g})$ was extracted by adding $50 \mathrm{ml}$ of aqueous ethanol at a ratio of 1:10 and agitated at $150 \mathrm{rpm}$ at room temperature $\left(25^{\circ} \mathrm{C}\right)$ for 60 min using a Incu-Shake MINI benchtop incubated shaker (SciQuip, Staffordshire, UK). The residues were removed by filtration using Whatman No. 1 filter papers. The residues were collected, re-extracted with the aqueous solvent, and centrifuged at $4500 \mathrm{rpm}$ for 15 min using a benchtop centrifuge Mikro 200 (Hettich, Tuttlingen, Germany). The supernatants were concentrated using a Rotavapor ${ }^{\circledR}$ R-210 rotary evaporator (Buchi, Flawil, Switzerland) at $40^{\circ} \mathrm{C}$. The concentrated extract was freeze-dried and stored at $-20^{\circ} \mathrm{C}$ until further analysis. The peel powder was extracted in triplicate for each extraction condition. 
Experimental design. Single factor experiment was used to determine the optimum extraction condition for passion fruit peel. The influence of extraction parameters, namely ethanol concentration, extraction time, and extraction temperature on DPPH radical scavenging activity for the passion fruit peel were studied [Thoo et al. 2010]. Different ethanol concentrations $(0,20,40,60,80$ and $100 \%, v / v)$ were first applied with other variables remained constant at room temperature $\left(25^{\circ} \mathrm{C}\right)$ for $60 \mathrm{~min}$. Then different extraction times of $60,120,180,240$, and $300 \mathrm{~min}$ at room temperature were applied using the best ethanol concentration determined. Finally, the extraction was carried out based on different extraction temperatures $\left(25,30,40,50\right.$ and $\left.60^{\circ} \mathrm{C}\right)$ applying the best ethanol concentration and extraction time. The best ethanol concentration, extraction time and extraction temperature were determined based on the highest DPPH radical scavenging activity. Based on the screening tests, $500 \mu \mathrm{g} / \mathrm{ml}$ extract yielded the highest DPPH radical scavenging activity compared to other extract concentrations $(100,200$, and $300 \mu \mathrm{g} / \mathrm{ml})$. Therefore, 500 $\mu \mathrm{g} / \mathrm{ml}$ of the extract was applied in this study. To determine the $\mathrm{EC}_{50}$ values for DPPH and ABTS assays, $100-500 \mu \mathrm{g} / \mathrm{ml}$ of the extract and synthetic antioxidants (BHA and $\alpha$-tocopherol) were used to plot the standard calibration curve for calculation of $\mathrm{EC}_{50}$ value. The synthetic antioxidants $(500 \mu \mathrm{g} / \mathrm{ml})$ were used for comparative purposes.

Determination of total phenolic content. Total phenolic content (TPC) was measured spectrophotometrically based on a method described by Ferreira et al. [2007]. Firstly, $1 \mathrm{ml}$ of sample extract was mixed with $4 \mathrm{ml}$ of Folin-Ciocalteu reagent (previously diluted 10 times) and the mixture was allowed to stand for $3 \mathrm{~min}$ at room temperature. Then, $5 \mathrm{ml}$ of $7.5 \%$ sodium carbonate solution was added to the mixture, vortexed vigorously and kept at room temperature in dark for $30 \mathrm{~min}$. The absorbance was measured at $765 \mathrm{~nm}$ using a PRIM Light spectrophotometer (Secomam, Cedex, France) against a blank (distilled water). The standard curve of gallic acid was $y=0.0165 x+0.0003$ $\left(\mathrm{R}^{2}=0.9972\right)$. TPC was expressed as $\mu \mathrm{g}$ gallic acid equivalent (GAE) per gram sample (fresh weight).

DPPH radical scavenging assay. DPPH radical scavenging activity of passion fruit peel was determined according to a method of Tsai et al. [2009]. Sample extract $(1 \mathrm{ml})$ was added with $500 \mu \mathrm{l}$ of DPPH solution (final concentration of $0.2 \mathrm{mM}$ in ethanol) in a test tube. The mixture was swirled vigorously using a vortex mixer VTX-3000L (LMS, Tokyo, Japan), and kept in dark for $30 \mathrm{~min}$. Then, the absorbance of the mixture was measured using the spectrophotometer at $517 \mathrm{~nm}$ against ethanol blank, and distilled water was used as negative control. Scavenging activity of the sample extract was calculated based on the equation below:

$$
\begin{aligned}
& \text { DPPH radical scavenging activity }(\%)= \\
& \quad=\left[1-\left(\mathrm{Abs}_{\text {sample }} / \mathrm{Abs}_{\text {control }}\right)\right] \times 100
\end{aligned}
$$

The calibration for the percentage of scavenging activity was plotted against logarithm ( $\mathrm{Log}$ ) of extract concentration to calculate $\mathrm{EC}_{50}$ that defined as the concentration of the extract to reduce the initial DPPH concentration by $50 \%$, where $\mathrm{EC}_{50}$ was obtained from a linear regression equation. BHA and $\alpha$-tocopherol were used as comparative standards.

ABTS radical inhibition activity. A modified procedure as described by Re et al. [1999] was applied to perform ABTS [2,2'-azino-bis(3-ethylbenzthiazoline-6-sulphonic acid)] assay by reacting $5 \mathrm{ml}$ of $7 \mathrm{mM}$ ABTS with $88 \mu \mathrm{l}$ of $140 \mathrm{mM}$ potassium persulfate $\left(\mathrm{K}_{2} \mathrm{~S}_{2} \mathrm{O}_{8}\right)$ in a reagent bottle. The mixture was kept in dark for 16-18 $\mathrm{h}$ at room temperature to allow complete generation of ABTS radical cation $\left(\mathrm{ABTS}^{++}\right)$. The mixture was then diluted with $95 \%$ ethanol in order to obtain an absorbance of $0.70 \pm 0.05$ when measured using the spectrophotometer at $734 \mathrm{~nm}$. Sample extract $(100 \mu \mathrm{l})$ was mixed with $1 \mathrm{ml}$ of the ABTS reagent. The mixture was vortexed and incubated for $6 \mathrm{~min}$ at room temperature before the absorbance was measured at $734 \mathrm{~nm}$ against ethanol blank. Distilled water $(100 \mu \mathrm{l})$ was used as control. BHA and $\alpha$-tocopherol were for comparison. The inhibition activity was calculated based on the following equation:

$$
\begin{gathered}
\text { ABTS radical inhibition ability }(\%)= \\
\quad=\left[1-\left(\mathrm{A}_{\text {sample }} / \mathrm{A}_{\text {control }}\right)\right] \times 100
\end{gathered}
$$

Ferric reducing antioxidant power assay. Ferric reducing antioxidant power (FRAP) assay was conducted according to a method of Wojdyło et al. [2007] with slight modification. FRAP reagent was prepared by mixing $10 \mathrm{mM}$ 2,4,6-tri(2 pyridyl)-s-triazine (TPTZ) in $40 \mathrm{mM} \mathrm{HCl}$ with $20 \mathrm{mM}$ ferric trichloride hexahydrate $\left(\mathrm{FeCl}_{3} \cdot 6 \mathrm{H}_{2} \mathrm{O}\right)$ and $0.3 \mathrm{M}$ acetate buffer 
$(\mathrm{pH}$ 3.6) at a ratio of 10:1:1 (v/v/v). The FRAP reagent was kept in a water bath WB/OB 7-45 (Memmert $\mathrm{GmbH} \& \mathrm{Co} . \mathrm{KG}$, Schwabach, Germany) at $37^{\circ} \mathrm{C}$ for $10 \mathrm{~min}$. The FRAP reagent $(1.5 \mathrm{ml})$ was added with $50 \mu 1$ of sample extract, and then the mixture was swirled and incubated for $4 \mathrm{~min}$. The absorbance was measured at $593 \mathrm{~nm}$ against a blank (FRAP reagent). BHA and $\alpha$-tocopherol were for comparison. FRAP value was calculated based on a calibration curve plotted against various concentrations of Trolox (10-400 $\mu \mathrm{g} / \mathrm{ml}$ ), and the result was expressed as Trolox equivalent antioxidant capacity ( $\mu \mathrm{g} \mathrm{TE} / \mathrm{g}$ sample). The calibration equation was $\mathrm{y}=0.005 \mathrm{x}-0.021\left(\mathrm{R}^{2}=0.998\right)$.

$\beta$-Carotene bleaching assay. $\beta$-Carotene bleaching (BCB) assay was conducted based on a method described by Yawadio et al. [2008] with slight modification. To prepare the working reagent, $200 \mu \mathrm{g}$ of $\beta$-carotene was dissolved in $1 \mathrm{ml}$ of chloroform, and then mixed with $0.02 \mathrm{ml}$ of linolenic acid and $0.2 \mathrm{ml}$ of Tween 40 in a round bottom flask. The chloroform in the mixture was removed under vacuum at $40^{\circ} \mathrm{C}$ using the rotary evaporator. The remaining solution was diluted with $50 \mathrm{ml}$ of oxygenated water and shaken vigorously to form an emulsion mixture. The assay was performed by addition of $0.5 \mathrm{ml}$ of sample extract to $4.0 \mathrm{ml}$ of the emulsion mixture. The mixture was immediately placed into the water bath for $2 \mathrm{~h}$ at $50^{\circ} \mathrm{C}$. The absorbance (at $470 \mathrm{~nm}$ ) of the mixture was measured at $0 \mathrm{~min}$ and at $20 \mathrm{~min}$ interval until $120 \mathrm{~min}$ of incubation. BHA and $\alpha$-tocopherol were used for comparison. The degradation rate of the sample was calculated based on the formula as follows:

$$
\begin{gathered}
\text { Degradation rate }(\mathrm{R})= \\
=\ln \left(\mathrm{abs}_{\mathrm{t}=0} / \mathrm{abs}_{\mathrm{t}=20,40,60,80,100, \text { and } 120 \mathrm{~min}}\right) / \mathrm{t}
\end{gathered}
$$

where $\ln$ is the natural $\log$ and $t$ is the initial absorbance at $0,20,40,60,80,100$, or $120 \mathrm{~min}$. Antioxidant activity (AA) was calculated as percentage of inhibition relative to control using the equation as follows:

$$
\% \mathrm{AA}=100 \times\left(\mathrm{R}_{\text {control }}-\mathrm{R}_{\text {sample }}\right) / \mathrm{R}_{\text {control }}
$$

where $\mathrm{R}_{\text {control }}$ and $\mathrm{R}_{\text {sample }}$ are the degradation rate in the emulsion without antioxidant and with sample extract, respectively.

Statistical analysis. All data were expressed as mean \pm standard deviation, and analysed using the SPSS statistical software version 20 (SPSS Inc., Illinois,
USA). The data were analysed using one-way analysis of variance (ANOVA) and post-hoc Bonferroni's test for means comparison. Pearson correlation test was used to determine the correlations between TPC and antioxidant activities (DPPH, ABTS, FRAP and BCB). The level of significance was set at $\mathrm{p}<0.05$.

\section{RESULTS AND DISCUSSION}

Effect of different extraction conditions on DPPH radical scavenging activity. The effects of different ethanol concentrations, extraction times, and extraction temperatures on percentages of DPPH radical scavenging activity for the passion fruit peel are shown in Figure 1. Different percentages of ethanol used significantly affected $(\mathrm{p}<0.05)$ the DPPH radical scavenging activity of the passion fruit peel extract. The highest percentage of scavenging activity was determined for $40 \%$ ethanol, followed by $60 \%, 80 \%, 20 \%$, and $0 \%$ ethanol. The used of $100 \%$ ethanol for the extraction of passion fruit peel gave the significantly lowest percentage of DPPH radical scavenging activity (Fig. 1 A). Based on the result obtained, it could be postulated that the passion fruit peel has a wide range of phenolic compounds with different polarities.

By considering the high DPPH radical scavenging activity obtained, $40 \%$ ethanol was chosen as the best extraction solvent for further extraction steps applying different extraction times. Similarly, $40 \%$ ethanol was also found to be most effective in extracting catechins from green and white tea [Rusak et al. 2008]. Our result is in agreement with some of the studies that binary solvent system particularly aqueous alcohol was more effective than mono-solvent system in extracting antioxidant compounds [Choi et al. 2006, Ghafoor et al. 2009]. Aqueous ethanol is commonly used in extraction of antioxidants in plant [Chew et al. 2012]. Higher DPPH radical scavenging activity should be found in alcoholic extracts compared to water extract because alcoholic solvent maximizes the interaction of DPPH radicals with antioxidants present in the sample [Spigno et al. 2007].

As shown in Figure $1 \mathrm{~B}$, the percentages of DPPH radical scavenging activity of the passion fruit peel extract were significantly different among the different extraction times. The result showed that 60 min extraction time yielded the highest percentage of scavenging 

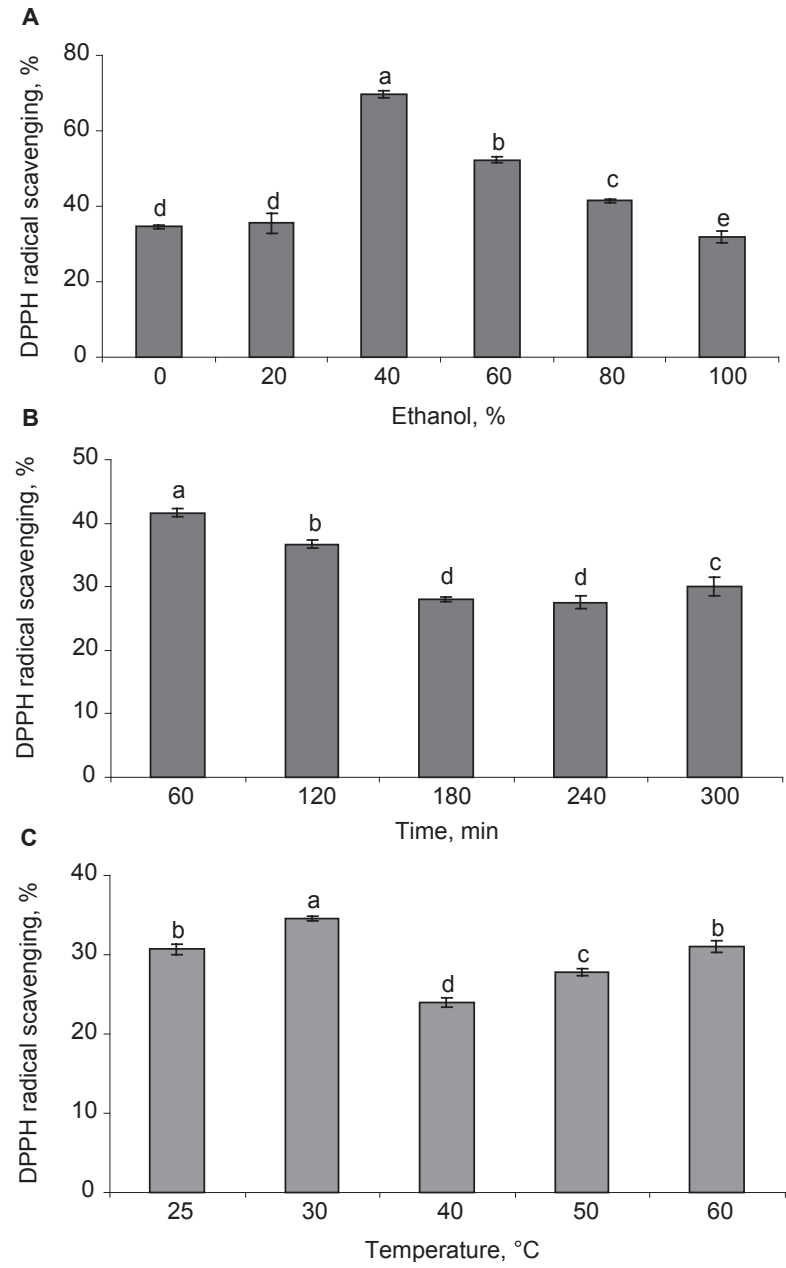

Fig. 1. Effect of (A) ethanol concentration, (B) extraction time and $(\mathrm{C})$ extraction temperature on DPPH radical scavenging activity of passion fruit peel extract. Values are presented as mean \pm standard deviation of triplicate analyses. Different lower case letters (a-e) denote significant differences at $\mathrm{p}<0.05$

activity, followed by $120 \mathrm{~min}$ and $300 \mathrm{~min}$. While 180 min and 240 min of extraction had the lowest percentages of scavenging activity, where no significant difference was found for the percentages of scavenging activity between $180 \mathrm{~min}$ and $240 \mathrm{~min}$ of extraction. The decrease in the scavenging activity after $60 \mathrm{~min}$ extraction time could be explained by the Fick's second law of diffusion, where final equilibrium among the solute concentrations in the solid matrix and in solvent was estimated to be achieved after 1-2 $\mathrm{h}$ of extraction duration [Silva et al. 2007]. Longer extraction time might increase the oxidation of phenolic compounds, thus contributing to lower DPPH radical scavenging activity [Naczk and Shahidi 2006]. The use of different extraction times to extract phenolic compounds may be due to the varying degrees of phenolic polymerization, solubility of phenolics and interaction between phenolic compounds and sample extract [Silva et al. 2007], where the final equilibrium between solvent and solid diffusion was attained exactly at an optimum extraction point [Lee et al. 1986]. After considering the cost of extraction time and its practicality based on the high scavenging activity, the best extraction time for extraction of antioxidants in the passion fruit peels was $60 \mathrm{~min}$.

Applying both $40 \%$ ethanol and 60 min extraction time, the uses of different extraction temperatures have significantly affected the percentages of DPPH radical scavenging activity of the passion fruit peel extract (Fig. $1 \mathrm{C}$ ). The results demonstrated that $30^{\circ} \mathrm{C}$ was the best extraction temperature, which gave the significantly highest scavenging activity compared to the other extraction temperatures used $(\mathrm{p}<0.05)$. Applying $>40^{\circ} \mathrm{C}$ of heat during the extraction has significantly reduced the percentage of scavenging activity. However, no significant difference was found for the percentages of scavenging activity between $25^{\circ} \mathrm{C}$ and $60^{\circ} \mathrm{C}$ of heat treatment. The DPPH radical scavenging activity was enhanced when the extraction temperature increased from $25^{\circ} \mathrm{C}$ to $30^{\circ} \mathrm{C}$. Liquid-solid extraction is a mass transport phenomenon where sample matrix migrates into solvent and in contact with the matrix [Corrales et al. 2009]. It can be enhanced by altering the extraction temperature, extraction time or solvent concentration. It was reported that an increase in temperature favoured extraction, increased bond dissociation energy of phenolic compounds, as well as enhanced solubility and diffusion coefficients of the compounds [Spigno et al. 2007]. On the contrary, a high extraction temperature $\left(>40^{\circ} \mathrm{C}\right)$ will cause some loss of organic solvent through evaporation, and also degradation of bioactive compounds [Naczk and Shahidi 2006]. Taking into consideration from the industrial point of view, higher extraction temperature $\left(>30^{\circ} \mathrm{C}\right)$ increase the usage of organic solvent and electrical cost, selection of $30^{\circ} \mathrm{C}$ would be the most appropriate extraction temperature for the passion fruit peel to maximize the extraction yield and minimize degradation of antioxidants at high temperature. 
TPC and antioxidant activity of passion fruit peel. Selection of the best extraction condition (40\% ethanol, 60 min extraction time, and $30^{\circ} \mathrm{C}$ extraction temperature) had yield at optimal level of antioxidant properties for the passion fruit peel. As depicted in Table 1 , the result showed that applying the best extraction condition, $15.84 \mu \mathrm{g}$ gallic acid equivalent (GAE) per $\mathrm{g}$ sample was determined for the passion fruit peel. Moderate level of antioxidant activity was also determined for the passion fruit peel. Assessed using FRAP and $\mathrm{BCB}$ assays, the extract of passion fruit peel had $30.94 \mu \mathrm{g}$ TE/g sample and $68.54 \%$ of inhibition, respectively (Table 1). However, a high $\mathrm{EC}_{50}$ values $(>500 \mu \mathrm{g} / \mathrm{ml}$ extract) that obtained from DPPH and ABTS assays were calculated for the passion fruit peel extract. This shows that antioxidants in the passion fruit peel extract did not strongly prevent decolorization of DPPH radical cation. It may be due to the moderately low level of TPC in the extract. On the other hand, applying similar concentration as for the extract, BHA and $\alpha$-tocopherol had extremely high antioxidant activities. As shown in Table 1, the $\mathrm{EC}_{50}$ values of the synthetic antioxidant were lesser than $0.01 \mu \mathrm{g} / \mathrm{ml}$. It shows that a low amount of the synthetic antioxidant is needed to give $50 \%$ of the inhibition activity. Besides, the synthetic antioxidant also had high TE values and inhibition percentages of BCB (Table 1). BHA had significantly higher TE values than $\alpha$-tocopherol; while the $\mathrm{BCB}$ inhibition percentages of both of the antioxidant standards were not significantly differed, where both of the synthetic antioxidant had $>96 \%$ of inhibition activities. Antioxidant activities of the passion fruit peel extracts were all significantly lower $(\mathrm{p}<0.05)$ than $\alpha$-tocopherol and BHA.

Optimization of solvent concentration, extraction time and extraction temperature is important for extraction of phenolic compounds from natural sources [Spigno et al. 2007]. Although the extraction method was optimized, low inhibition abilities of the antioxidants in the passion fruit peel extract were determined using DPPH and ABTS assays. Similarly, a low FRAP value was also obtained for the extract. A possible explanation for the low antioxidant activities that assessed using these antioxidant assays is the antioxidants extracted using these optimized extraction condition, especially the use of aqueous ethanol is not a strong reducing agents as moderately level of TPC was determined. According to Huang et al. [2005], DPPH, ABTS and FRAP assays were categorised as antioxidant assays involving electron-transfer reaction pathways. Antioxidants in any extracts must be strong reducing agents to reduce the radical cations generated in the reagents. In this case, the low TPC in the passion fruit peel extract has proven that the peel extract should be containing other phytochemical besides phenolic compounds. It was supported by the moderately BCB inhibition activity of the passion fruit peel extract as the antioxidants in the extract were moderately inhibited the bleaching of $\beta$-carotene under oxidative stress condition.

Other than the assays involve electron-transfer reaction pathway, $\mathrm{BCB}$ assay involves hydrogen transfer

Table 1. Total phenolic content (TPC) and antioxidant activities of passion fruit peel extracts based on the chosen extraction conditions ( $40 \%$ ethanol, $30^{\circ} \mathrm{C}$ and $60 \mathrm{~min}$ of extraction)

\begin{tabular}{lccccc}
\hline \multirow{2}{*}{ Sample } & TPC, $\mu \mathrm{g} \mathrm{GAE} / \mathrm{g}$ & \multicolumn{2}{c}{$\mathrm{EC}_{50}, \mu \mathrm{g} / \mathrm{ml}$} & \multirow{2}{*}{ FRAP, $\mu \mathrm{g}$ TE/g } & \multirow{2}{*}{ BCB, \% } \\
\cline { 3 - 4 } & & $\mathrm{DPPH}$ & ABTS & & \\
\hline Passion fruit peel & $15.84 \pm 0.63$ & $>500$ & $>500$ & $30.94 \pm 2.96^{\mathrm{c}}$ & $68.54 \pm 7.52^{\mathrm{b}}$ \\
BHA & - & $<0.01$ & $<0.01$ & $861.84 \pm 21.51^{\mathrm{a}}$ & $98.91 \pm 0.26^{\mathrm{a}}$ \\
$\alpha$-Tocopherol & - & $<0.01$ & $<0.01$ & $352.23 \pm 26.87^{\mathrm{b}}$ & $96.36 \pm 0.23^{\mathrm{a}}$ \\
\hline
\end{tabular}

Each value was expressed as mean \pm standard deviation of triplicate analyses, except for $\mathrm{EC}_{50}$ value. Different superscripts lower case letters (a-c) within the same column for FRAP and BCB assays denote significantly different at $\mathrm{p}<0.05$. $\mathrm{EC}_{50}$ values for DPPH and ABTS assays were calculated by interpolation of linear regression analysis (based on concentrationdependent result - data not shown). It was defined as effective concentration that able to scavenge $50 \%$ of the total DPPH/ ABTS radicals. 
reaction pathway. Any non-reducing antioxidant is also able to inhibit the degradation of $\beta$-carotene due to increasing oxidative stress. Based on the morphology of passion fruit peel, the peel has whitish inner layer and purplish outer layer. Yapo and Koffi [2008] reported that the peel of passion fruit was rich in dietary fiber. Mandelonitrile glycosides have been isolated from the passion fruit peel [Chassagne et al. 1996]. These compounds could have low antioxidant activity and possibly acted as pro-oxidant. On the other hand, previous studies have shown that higher ABTS radical scavenging activity was found in hydrophilic than hydrophobic extracts [Gao et al. 2000, Zieliński and Kozłowska 2000], while another study also showed that DPPH assay was limited to interpreting hydrophobic antioxidants [Huang et al. 2005]. Hence, it could possibly be deduced that the antioxidants present in passion fruit peel may possess more lipophilic in nature. BCB assay has also simulates membrane based lipid oxidation [Prior et al. 2005]. Besides, antioxidants in food are normally referred to any substances that can inhibit fatty acid autoxidation [Huang et al. 2005]. Since passion fruit peel extract showed moderate BCB activity, the passion fruit peel can be considered as a potential source of antioxidants.

Correlations between TPC and antioxidant activities. The Pearson correlation coefficient values (r) determined for the TPC and antioxidant activities of the passion fruit peel extract are shown in Table 2. In this study, Pearson correlation coefficients (r) between the TPC and antioxidant activities (DPPH, ABTS, FRAP, and BCB assays) of the extract were ranged between 0.878 and 0.996 . The results showed that positive and very high correlations were found among the TPC and antioxidant activities, except the antioxidant activity for $\mathrm{BCB}$ assay. According to the Guildford's rule of thumb, $r \geq 0.9$ is considered very

Table 2. Correlations between TPC and antioxidant activities (DPPH, ABTS, FRAP, and BCB assays) of the passion fruit peel extracted based on the chosen extraction conditions $\left(40 \%\right.$ ethanol, $30^{\circ} \mathrm{C}$ and $60 \mathrm{~min}$ of extraction)

\begin{tabular}{ccccc}
\hline Assay & DPPH & ABTS & FRAP & BCB \\
\hline TPC & 0.991* & $0.963^{*}$ & $0.996^{*}$ & $0.878^{*}$ \\
\hline
\end{tabular}

*All values were significant at $\mathrm{p}<0.01$. high correlation (Guildford 1973). The correlation coefficient value (r) between TPC and BCB inhibition was 0.878 . Referring to the rule of thumb, a positive and high correlation was determined between TPC and BCB inhibition. All the correlation coefficients determined were significant at $\mathrm{p}<0.01$.

A high correlation for the TPC and antioxidant activity indicated that high amount of total phenolics in the passion fruit peel will give rise to high antioxidant activity for the peel. Very high correlations were determined for the TPC and the three electron-transfer based assays proven that the passion fruit peel contained phenolic compounds that are strong reducing agents. Although the correlation value for TPC and BCB inhibition activity was not very high, these strong reducing agents (antioxidants) in the passion fruit peel are also able to inhibit the degradation of beta carotene. As mentioned earlier, due to the low TPC and high $\mathrm{EC}_{50}$ values determined for the passion fruit peel extract, a very high positive correlation was found for the TPC and antioxidant activity does not mean that the passion fruit peel has high antioxidant properties. Based on this finding, we assumed that the antioxidants present in passion fruit peel would probably be flavonoids or terpenoids as DPPH radical cation known to react specifically with low molecular weight phenolic compounds [Paixão et al. 2007]. The results of this study are also consistent with the finding by Wangcharoen and Morasuk [2007] that TPC were significantly correlated with FRAP, DPPH, and ABTS in some Thai culinary plants.

Antioxidant activity is not only contributed by phenolic compounds, other compounds such as ascorbic acid, tocopherols, carotenoids, reduced carbohydrates, and terpenes, as well as the synergistic effects among the antioxidants could also contribute to the total antioxidant activity of a particular sample matrix [Babbar et al. 2011]. The very high correlations between TPC and antioxidant activities (FRAP, ABTS, or DPPH) were not surprising due to the similarity of the redox reactions between these assays [Huang et al. 2005]. Further studies should be carried out to identify the potential phenolic compounds that contributed to the antioxidant activity. Perhaps, some of the unknown compounds in the passion fruit peel could have contributed to the antioxidant activity, thus more studies are needed to determine the relationship between these unknown and their antioxidant activities. 


\section{CONCLUSION}

Different extraction conditions affected the TPC and antioxidant activities of passion fruit peel. Passion fruit peel extracted using the best extraction condition $\left(40 \%\right.$ ethanol as extraction solvent, $30^{\circ} \mathrm{C}$ of extraction temperature and $60 \mathrm{~min}$ of extraction time) had an optimal antioxidant activity. A moderate level of TPC (15.84 $\mu \mathrm{g} \mathrm{GAE/g} \mathrm{sample)} \mathrm{was} \mathrm{determined} \mathrm{in} \mathrm{the} \mathrm{pas-}$ sion fruit peel extract, while the antioxidant activities assessed using different antioxidant assays were varied. Due to the moderate level of TPC as antioxidants in the peel extract, the antioxidants could not be acting as strong reducing agents to give lower $\mathrm{EC}_{50}$ and higher TE values compared to the synthetic antioxidants. However, the peel extract was able to give $68.54 \%$ of inhibition activity for BCB assay. Therefore, the peel of passion fruit is still considered as a good source of antioxidant. It can also be used as potent source of pharmaceutical ingredient. In future, more studies are needed to identify the potential bioactive compounds in passion fruit peel and the related health benefits.

\section{ACKNOWLEDGEMENT}

The authors are grateful to UCSI University for providing financial support under the Research Grant Scheme (Proj-In-FAS-006).

\section{REFERENCES}

Anwar F., Przybylski R., 2012. Effect of solvents extraction on the total phenolics and antioxidant activity of extracts from flaxseed (Linum usitatissimum L.). Acta Sci. Pol., Technol. Aliment. 11, 293-301.

Babbar N., Oberoi H.S., Uppal D.S., Patil R.T., 2011. Total phenolic content and antioxidant capacity of extracts obtained from six important fruit residues. Food Res. Int. 44, 391-396.

Chantaro P., Devahastin S., Chiewchan N., 2008. Production of antioxidant high dietary fiber powder from carrot peels. LWT-Food Sci. Technol. 41, 1987-1994.

Choi Y., Lee S.M., Chun J., Lee H.B., Lee J., 2006. Influence of heat treatment on the antioxidant activities and polyphenolic compounds of shiitake (Lentinus edodes) mushroom. Food Chem. 99, 381-387.

Chassagne D., Crouzet J.C., Bayonove C.L., Baumes R.L., 1996. Identification and quantification of passion fruit cyanogenic glycosides. J. Agric. Food Chem. 44, 3817-3820.

Chew L.Y., Khoo H.E., Amin I., Azrina A., Lau C.Y., 2012. Analysis of phenolic compounds of dabai (Canarium odontophyllum Miq.) fruits by high-performance liquid chromatography. Food Anal. Methods 5, 126-137.

Corrales M., Garcia A.F., Butz P., Tauscher B., 2009. Extraction of anthocyanins from grape skins assisted by high hydrostatic pressure. J. Food Eng. 90, 415-421.

Halliwell B., 2012. Free radicals and antioxidants: Updating a personal view. Nutr. Revs. 70, 257-265.

Farid R., Rezaieyazdi Z., Mirfeizi Z., Hatef M.R., Mirheidari M., Mansouri H., Esmaellie H., Bentley G., Lu Y., Foo Y., Watson R.R., 2010. Oral intake of purple passion fruit extract reduces pain and stiffness and improves physical function in adult patients with knee osteoarthritis. Nutr. Res. 30, 601-606.

Ferreira I.C.F.R., Baptista P., Vilas-Boas M., Barros L., 2007. Free radical scavenging capacity and reducing power of wild edible mushrooms from northeast Portugal: Individual cap and stipe activity. Food Chem. 100, 1511-1516.

Gao X., Bjork L., Trajkovski V., Uggla M., 2000. Evaluation of antioxidant activities of rosehip ethanol extracts in different test systems. J. Sci. Food Agric. 80, 2021-2027.

Ghafoor K., Choi Y.H., Jeon J.Y., Jo I.N., 2009. Optimization of ultrasound-assisted extraction of phenolic compounds, antioxidants and anthocyanins from grape (Vitis vinifera) seeds. J. Agric. Food Chem. 57, 4988-4994.

Gonzalez-Montelongo R., Gloria Lobo M., Gonzalez M., 2010. Antioxidant activity in banana peel extracts: Testing extraction conditions and related bioactive compounds. Food Chem. 119, 1030-1039.

Guildford J.P., 1973. Foundamental statistics in psychology and education. McGraw-Hill New York.

Hooper J., 1994. Tropical fruit juices: Passion fruit. In: Production and packaging of non-carbonated fruit juices and fruit beverages. Ed. P.R. Ashurst. Aspen Publ. New York, 114-116.

Huang D.J., Ou B.X., Prior R.L., 2005. The chemistry behind antioxidant capacity assays. J. Agric. Food Chem. 53, 1841-1856.

Janick J., Paull R.E., 2008. Passiflora edulis. In: Encyclopedia of fruit and nuts. CAB Int. Pub. UK, 586-595.

Kuljarachanan T., Devahastin S., Chiewchan N., 2009. Evolution of antioxidant compounds in lime residues during drying. Food Chem. 113, 944-949.

Lapornik B., Prosek M., Wondra A.G., 2005. Comparison of extracts prepared from plant by-products using different solvents and extraction time. J. Food Eng. 71, 214-222. 
Wong Y.S., Sia C.H., Khoo H.E., Ang Y.K., Chang S.K., Yim H.S., 2014. Influence of extraction conditions on antioxidant properties of passion fruit (Passiflora edulis) peel. Acta Sci. Pol., Technol. Aliment. 13(3), 257-265.

Lee A.K.K., Bulley N.R., Fattori M., Meisen A., 1986. Modelling of supercritical carbon dioxide extraction of canola oilseed in fixed beds. J. Am. Oil Chem. Soc. 63, 921-925.

Mittler R., Vanderauwera S., Suzuki N., Miller G., Tognetti V.B., Vandepoele K., Gollery M., Shulaev V., Breusegem F.V., 2011. ROS signaling: The new wave? Trends Plant Sci. 16, 300-309.

Naczk M., Shahidi F., 2006. Phenolics in cereals, fruits and vegetables: occurrence, extraction and analysis. J. Pharm. Biomed. Anal. 41, 1523-1542.

Paixão N., Perestrelo R., Marques J.C., Câmara J.S., 2007. Relationship between antioxidant capacity and total phenolic content of red, rosé and white wines. Food Chem. 105, 204-214.

Pinelo M., Rubilar M., Jerez M., Sineiro J., Nunez M.J., 2005. Effect of solvent, temperature, and solvent-tosolid ratio on the total phenolic content and antiradical activity of extracts from different components of grape pomace. J. Agric. Food Chem. 53, 2111-2117.

Prior R.L., Wu X., Schaich K., 2005. Standardized methods for the determination of antioxidant capacity and phenolics in foods and dietary supplements. J. Agric. Food Chem. 53, 4290-4302.

Re R., Pellegrini N., Proteggente A., Pannala A., Yang M., Rice-Evans C., 1999. Antioxidant activity applying an improved ABTS radical cation decolorization assay. Free Radical Biol. Med. 26, 1231-1237.

Rusak G., Komes D., Likíc S., Horžić D., Kovać M., 2008. Phenolic content and antioxidant capacity of green and white tea extracts depending on extraction conditions and the solvent used. Food Chem. 110, 852-858.

Sai-Ut S., Jongjareonrak A., Chaiwut P., Rawdkuen S., 2010. Extraction optimization of antioxidant from passion fruit seeds using response surface methodology. In: Proceedings of the Food Innovation Asia Conference. Bangkok, Thailand, 481-489.

Shui G., Leong L.P., 2006. Residue from star fruit as valuable source for functional food ingredients and antioxidant nutraceuticals. Food Chem. 97, 277-284.

Silva E.M., Rogez H., Larondelle Y., 2007. Optimization of extraction of phenolics from Inga edulis leaves using response surface methodology. Sep. Purif. Technol. 55, 381-387.
Spigno G., Tramelli L., Faveri D.M.D., 2007. Effects of extraction time, temperature and solvent on concentration and antioxidant activity of grape marc phenolics. J. Food Eng. 81, 200-208.

Suvarnakuta P., Chaweerungrat C., Devahastin S., 2011. Effects of drying methods on assay and antioxidant activity of xanthones in mangosteen rind. Food Chem. 125, 240-247.

Tsai S., Huang S., Lo S., Wu T., Lian P., Mau J., 2009. Flavour components and antioxidant properties of several cultivated mushrooms. Food Chem. 113, 578-584.

Thoo Y.Y., Ho S.K., Liang J.Y., Ho C.W., Tan C.P., 2010. Effects of binary solvent extraction system, extraction time and extraction temperature on phenolic antioxidants and antioxidant capacity from mengkudu (Morinda citrifolia). Food Chem. 120, 290-295.

Wangcharoen W., Morasuk W., 2007. Antioxidant capacity and phenolic content of some Thai culinary plants. Maejo Int. J. Sci. Technol. 1, 100-106.

Watson R.R., Zibadi S., Rafatpanah H., Jabbari F., Ghasemi R., Ghafari J., Afrasiabi H., Foo L.Y., Faridhosseini R., 2008. Oral administration of the purple passion fruit peel extract reduces wheeze and cough and improves shortness of breath in adults with asthma. Nutr. Res. 28, 166-171.

Wojdyło A., Oszmiański J., Czemerys R., 2007. Antioxidant activity and phenolic compounds in 32 selected herbs. Food Chem. 105, 940-949.

Yapo B.M., Koffi K.L., 2008. Dietary fiber components in yellow passion fruit rind - a potential fiber source. J. Agric. Food Chem., 56, 5880-5883.

Yawadio R., Kikuzaki H., Konishi Y., 2008. Antioxidant activity of various extracts and fractions of Chenopodium quinoa and Amaranthus spp. Seeds. Food Chem. 106, 760-766.

Zibadi S., Farid R., Moriguchi S., Lu Y., Foo L.Y., Tehrani P.M., Ulreich J.B., Watson R.R., 2007. Oral administration of purple passion fruit peel extract attenuates blood pressure in female spontaneously hypertensive rats and humans. Nutr. Res. 27, 408-416.

Zieliński H., Kozłowska H., 2000. Antioxidant activity and total phenolics in selected cereal grains and their different morphological fractions. J. Agric. Food Chem. 48, 2008-2016.

Accepted for print - Zaakceptowano do druku: 22.03.2014

For citation - Do cytowania

Wong Y.S., Sia C.H., Khoo H.E., Ang Y.K., Chang S.K., Yim H.S., 2014. Influence of extraction conditions on antioxidant properties of passion fruit (Passiflora edulis) peel. Acta Sci. Pol., Technol. Aliment. 13(3), 257-265. 